\title{
A capillary zone electrophoresis for determination of thiolic peptides in biological samples
}

\author{
Mónica Pérez-Rama, Julio Abalde, Concepción Herrero, Cristina \\ Suárez, Enrique Torres
}

Laboratorio de Microbiología, Facultad de Ciencias, Universidade da Coruña, A Coruña, Spain

Journal of Separation Science, Volume 32, Issue 12, June 2009, Pages 2152-2158

First published: 22 June 2009, Accepted: 2 April 2009, Received: 16 February 2009

This is the peer reviewed version of the following article:

Pérez-Rama, M., Abalde, J., Herrero, C., Suárez, C. and Torres, E. (2009), A capillary zone electrophoresis for determination of thiolic peptides in biological samples. J. Sep. Science, 32: 2152-2158. doi:10.1002/jssc.200900104

which has been published in final form at http://dx.doi.org/10.1002/jssc.200900104 . This article may be used for non-commercial purposes in accordance with Wiley Terms and Conditions for Self-Archiving.

\begin{abstract}
A new method to improve the analyses of thiolic peptides (cysteine, $\gamma$ Glu-Cys, glutathione, phytochelatins and desglycyl-phytochelatins) derivatized with monobromobimane $(\mathrm{mBrB})$ in complex biological samples by CZE is described. The method involves a SPE using Sep-Pak Light C18 Cartridges after derivatization and a later CZE analysis. Elution of mBrB-thiols was achieved with $10 \mathrm{mM} \mathrm{HCl}+70 \%$ methanol $\mathrm{v} / \mathrm{v}$ in deionised water. Electrophoretic parameters, such as BGE $\mathrm{pH}$ and concentration, different organic additives (methanol and trifluoroethanol), applied voltage and capillary length were studied in order to establish suitable analytical conditions. Optimum separation of the mBrB-thiolic peptides was obtained with 100
\end{abstract}


$\mathrm{mM}$ sodium borate buffer at $\mathrm{pH}$ 7.60. The electrophoretic conditions were $+15 \mathrm{kV}$, capillary length of $90 \mathrm{~cm}$ from inlet to detector ( $98 \mathrm{~cm}$ total length, $50 \mu \mathrm{m} \mathrm{ID),} \mathrm{samples}$ were loaded into the capillary by hydrodynamic injection (50 mbar, $20 \mathrm{~s}$ ) and detection was performed at $390 \mathrm{~nm}$. The improved method showed good reproducibility, linearity and sensitivity. The LODs and LOQs estimated using a standard of GSH were 1.41 and $4.69 \mu \mathrm{M}$ respectively.

\section{Keywords:}

Capillary zone electrophoresis / Cysteine / Glutathione / Phytochelatins / Thiols

Sulphur (S) is an essential macronutrient. It is taken up as sulphate by autotrophic organisms and it is assimilated into cysteine (Cys), an amino acid at the cross roads of primary metabolism, protein synthesis and the formation of low molecular weight sulphur-containing defence compounds (glutathione (GSH) ( $\gamma$-Glu-Cys-Gly), phytochelatins, various secondary metabolites and other sulphur-rich polypeptides). Sulphur-containing defence compounds are crucial for the survival of organisms under biotic and abiotic stress [1].

The most important/critical low molecular weight biological thiols are GSH and Cys. Cys is synthesized in the final step of the sulphate reduction pathway by the enzyme Cys synthase and it is incorporated into sulphurrich proteins and GSH. The amount of GSH in a given organism is the result of the combined action of biosynthesis, consumption and degradation. GSH protects the cytosol and other cellular compartments against reactive oxygen species, which accumulate in response to biotic and abiotic stress. In the ascorbate-GSH cycle, the function of GSH is linked to that of ascorbic acid and electron flow from NADPH. Moreover, GSH also operates as a component in GSH S-transferase (GST)-based detoxification mechanisms. Finally, in fungi, plants and algae, under heavy-metal exposure, GSH is the precursor of phytochelatins, Cys-rich peptides synthesized via phytochelatin synthase [2], which have an important role in the mechanisms of metal detoxification [3]. Also, desglycyl phytochelatins (desGly-PC $\mathrm{C}_{\mathrm{n}}$, also known as d-PC ${ }_{\mathrm{n}}$ ) with $\mathrm{n} \gamma$-Glu-Cys subunits ( $\gamma$-GluCys) , PCs lacking terminal amino acid Gly, are involved in the tolerance mechanisms to metals. Qualitative and quantitative analyses of PCs and desGly-PCs provide useful information about how organisms respond to metals in the environment.

Several methods for analysis of thiols, in different biological matrices, have been described in the literature. The classical technique for analyses of these compounds is 
RP HPLC and it is still in use for their detection and quantification [4-6]. The derivatization with a specific chromogenic or fluorogenic compound provides better selectivity in the detection process. Monobromobimane (mBrB) (3,7-dimethyl-4brommethyl-6-methyl-1,5-diazabicyclo-[3.3.0]-octa-3,6-dien-2,8-dion) is a fluorogenic compound commonly used because it reacts with several low molecular weight thiols $[7,8]$. CE has proven being a good alternative to HPLC. Several CE methods have been reported for the determination of GSH, Cys or other thiols in biological samples [9-12]. However, few works of CE include the simultaneous separation of all these peptides (Cys, GSH, phytochelatins and desGly-PCs) in the same run.

The proposal of this study is the development of a method that allows analyzing different thiolic peptides in biological samples, in the same CE run. For this purpose, selective and accurate analytical methods are obviously required, because of the complex matrix of this type of samples. A clean-up of the sample, with SPE, before analyses was used to remove matrix ions which otherwise caused electrophoretic destacking. This step also allowed a preconcentration and acidification of the sample. With those conditions, separation buffer and electrophoretic parameters were considered to obtain an adequate resolution and separation efficiency of peaks in electropherograms.

The biological material chosen for the development of this procedure was the marine microalga Tetrase $\mu$ Mis suecica because the extracts obtained from this organism are very complex and previous works showed that Tetrase $\mu$ Mis produces a notable quantity of different thiol compounds (included phytochelatins and desGly-PCs) when it is exposed to cadmium [13].

The method developed offers an attractive approach for the analysis of thiols. Due to its simplicity and reliability, the developed procedure was convenient for routine analyses of biologically significant thiolic peptides in complex matrix.

\section{Materials and methods}

\section{Chemicals and reagents}

All chemicals used were of the highest purity available. Boric acid $\left(\mathrm{H}_{3} \mathrm{BO}_{3}\right)$, hydrochloric acid $(\mathrm{HCl})$, sodium hydroxide $(\mathrm{NaOH}), \mathrm{mBrB}\left(\mathrm{C}_{10} \mathrm{H}_{11} \mathrm{~N}_{2} \mathrm{O}_{2} \mathrm{Br}\right), 2$, 2,2trifluoroethanol $\left(\mathrm{C}_{2} \mathrm{H}_{3} \mathrm{~F}_{3} \mathrm{O}\right)$, sodium $\left(\mathrm{NaBH}_{4}\right)$, diethylenetriaminepentaacetic acid anhydride (DTPA) $\left(\mathrm{C}_{14} \mathrm{H}_{19} \mathrm{~N}_{3} \mathrm{O}_{8}\right)$, Cys $\left(\mathrm{C}_{3} \mathrm{H}_{7} \mathrm{NO}_{2} \mathrm{~S}\right)$, $\gamma$-Glu-Cys $\left(\mathrm{C}_{8} \mathrm{H}_{14} \mathrm{~N}_{2} \mathrm{O}_{5} \mathrm{~S}\right)$ and $\mathrm{GSH}\left(\mathrm{C}_{10} \mathrm{H}_{17} \mathrm{~N}_{3} \mathrm{O}_{6} \mathrm{~S}\right)$ were purchased from Sigma (St. Louis, MO, USA). Phytochelatin standards were purchased from bioNova (bioNova 
cient_fica s.1., Madrid, Spain). HPLCgrade methanol was purchased from Scharlau (Scharlau Chemie, S.A., Barcelona, Spain). NC filters were obtained from Millipore (Millipore Ib_rica, Madrid, Spain). $\mathrm{C}_{18}$ SPE columns (Sep-Pak Light C18 Cartridges) were obtained from Waters (Waters Corporation, USA).

The different reagents and buffers were prepared with water obtained from a Milli-Q system.

\section{Electrophoretic system}

All the electrophoretic experiments were performed in an $\mathrm{HP}^{3 \mathrm{D}} \mathrm{CE} \mathrm{CE}$ System (Agilent Technologies, Waldbronn, Germany) equipped with a photodiode array detector. The detection was set at a wavelength of $390 \mathrm{~nm}$. All system control, data collection, processing and analyses were performed using the Agilent ChemStation Software (Agilent Technologies, Waldbronn, Germany).

\section{Electrophoresis procedure}

A 70, 80 and $90 \mathrm{~cm}$ effective length (78,88 and $98 \mathrm{~cm}$ total length respectively), 50 $\mu \mathrm{m}$ ID and $375 \mu \mathrm{m}$ OD uncoated fused silica capillaries (Composite Metal Services Ltd., UK Block) were used for the method. The temperature of the cassette containing the capillary was maintained at $25^{\circ} \mathrm{C}$ with an air coolant control system.

Borate buffer with different $\mathrm{pHs}$ and concentrations was used as BGE for the separation. The $\mathrm{pH}$ of boric acid was adjusted with $1 \mathrm{M} \mathrm{NaOH}$ to obtain electrolytes with pHs from 7.1 to 7.8 .

In all cases, the $\mathrm{pH}$ was measured in a $720 \mathrm{~A}+$ Thermo $\mathrm{pH}$ meter (Thermo Electron Corporation, England). After the $\mathrm{pH}$ adjustments, the volume of the solution was adjusted to obtain final sodium borate concentrations of 25, 50, 75, 100 and $125 \mathrm{mM}$, each one with the range of $\mathrm{pHs}$ assayed.

Different concentrations of methanol or trifluoroethanol from 2.5 to $10 \% \mathrm{v} / \mathrm{v}$, dissolved in the BGE and used as organic modifiers, were also assayed.

All buffers were passed through a $0.22 \mu \mathrm{m} \mathrm{NC}$ filter and degassed before use.

Prior to the runs, the capillary was rinsed with $0.1 \mathrm{M} \mathrm{NaOH}$ solution followed by deionised water under a $50 \mathrm{mbar}$ internal pressure, each for $3 \mathrm{~min}$. Finally, it was conditioned with the BGE. The protocol for each sample run consisted of a $5 \mathrm{~min}$ prerinse with BGE followed by sample injection. Samples were loaded into the anodic inlet end of the capillary by hydrodynamic injection (50 mbar, $20 \mathrm{~s}$ ). 
The power supply was operated in the constant-voltage mode at $+15 \mathrm{kV}$. All electrophoretic separations were carried out at least in triplicate. Number of theoretical plates and resolution was calculated by software.

Linearity in a graphic of current versus voltage applied to the selected BGE (Ohm's law plot) was used to select the suitable voltage that could be utilized for the developed procedure. Different voltages $(1-30 \mathrm{kV})$ were applied to the finally selected BGE and the current was registered. A graphical representation with these two parameters was performed. The maximum voltage was indicated by the point at which nonlinearity occurs.

\section{Biological samples}

Biological samples of a marine microalga were used to develop this procedure. The marine microalga $\mathrm{T}$. suecica (Kylin) Butch was cultured in natural seawater enriched with inorganic nutrients without EDTA and Tris [14]. Cultures were grown in glass bottles (PYREX) with natural sterile air at a flow rate of $10 \mathrm{~L} / \mathrm{min}$. They were maintained at $18 \pm 1{ }^{\circ} \mathrm{C}$ and 68 (Einstein $/ \mathrm{m}^{2} / \mathrm{s}$, with a dark/light cycle of $12: 12 \mathrm{~h}$. Initial cell density was $25 \times 10^{4}$ cells $/ \mathrm{mL}$.

Cadmium was the metal used for the induction of phytochelatins. The marine microalga was exposed to $8 \mathrm{mg} / \mathrm{L}$ of this metal, added to the culture medium as $\mathrm{CdC}_{12}$.

After 7 days of culture, cells exposed to cadmium were collected by centrifugation (12000 x g for $10 \mathrm{~min})$. Samples were stored at $-20^{\circ} \mathrm{C}$ until analyses.

\section{Extraction and derivatization of low-molecularmassthiol compounds in biological samples using $\mathrm{mBrB}$}

The derivatization procedure was adapted from Pérez-Rama et al. [15]. Frozen samples were resuspended in an appropriate volume of $0.1 \mathrm{M} \mathrm{HCl}$. Cells were homogenized with an ultrasonic cell disrupter for $3 \mathrm{~min}$ at $150 \mathrm{~W}$ and $14 \mu \mathrm{m}$ amplitude.

Unbroken cells and cell debris were removed by centrifugation at $12000 \mathrm{x}$ g for 15 $\min$ at $4^{\circ} \mathrm{C}$. The supernatant was collected and $500 \mu \mathrm{L}$ was added to $500 \mu \mathrm{L}$ of a derivatization buffer freshly prepared. This buffer was composed of $1 \mathrm{M}$ sodium borate buffer (pH 9), $1 \mathrm{mM}$ DTPA and $1.5 \mathrm{mg} / \mathrm{L}$ of $\mathrm{NaBH}_{4}$.

Once the sample was mixed with the buffer, $8 \mu \mathrm{L}$ of $0.1 \mathrm{M} \mathrm{mBrB}$ dissolved in ACN were added and the mixture was incubated at room temperature in Eppendorf tubes for 1 
$\mathrm{h}$ in darkness. Samples were centrifuged at $12000 \mathrm{x} \mathrm{g}$ for $10 \mathrm{~min}$ at $4^{\circ} \mathrm{C}$. The supernatant was then concentrated and purified by means of SPE using Sep-Pak Light $\mathrm{C} 18$ cartridges. The column was activated with methanol and then rinsed with $10 \mathrm{~mL}$ of $10 \mathrm{mMHCl}$ plus $0.5 \% \mathrm{v} / \mathrm{v}$ methanol in deionised water. Samples of $2 \mathrm{ml}$ were introduced in the column and washed with $2 \mathrm{ml}$ of the rinsed solution. Finally, the mBrB-thiol compounds were eluted using $10 \mathrm{mM} \mathrm{HCl}$ plus $70 \%$ methanol v/v in deionised water. Using this procedure, the samples were acidified and it was not necessary to filter or centrifugate prior to injection into the CE system. $600 \mu \mathrm{L}$ of the sample was transferred to CZE vials for injection.

Standards of Cys, $\gamma$-Glu-Cys, GSH, phytochelatins and desGly-PCs derivatized in the same way, compared to biological samples, were used to identify the different peaks.

\section{Method validation}

To determine linearity, a regression line was calculated using GSH. A standard calibration graph was obtained for GSH in order to do a quantitative analyses of the different mBrB-thiolic peptides. The graph was constructed using GSH standards at concentration ranges from 7.5 to $100 \mu \mathrm{M}$, derivatized and processed as the biological samples, and finally analyzed by the CE procedure developed. The analyses was performed in triplicate for each concentration. The peak area obtained was plotted against the corresponding concentration of GSH $(\mu \mathrm{M})$ and the regression equation $(y=$ $a+b x$, where $\mathrm{x}$ was GSH concentration and $\mathrm{y}$ was the peak area) was determined by the least-squares method. LODs and LOQs were estimated in accordance with IUPAC.

A within-run precision for the method was obtained by injecting the same biological sample six times consecutively to the EC system and six times on different days to obtain the inter-day precision. Cys was taken as the reference peak (marker) to calculate the relative migration time (RMT) of other thiol compounds.

Accuracy was evaluated by means of recovery assays using the standard addition method. Two different standard analytes (Cys and GSH) were added to microalgal extracts before sample pre-treatment, in which the concentration of these analytes had already been determined. Three increasing known quantities (7.5, 40 and $100 \mu \mathrm{M})$ of these standards were added to three aliquots of microalgal extract. Following the procedure, the percentage of recovery rate was established from the response values obtained according to the calibration curve and the real concentration of the standard added. 
In this way, the total concentration of the standard was calculated after analyses and the percentage of recovery of added analyte was calculated by means of the equation: Recovery $(\%)=(100 \mathrm{x}$ total concentration measured (original concentration in sample))/added concentration.

Student's t-test was applied to determine if the recovery was satisfactory.

\section{Results and discussion}

In the present study, a SPE column (Sep-Pak Light C18 cartridge) was used to concentrate, acidify and clean up the sample to remove the matrix interferences. The thiol compounds were eluted from the SPE column using a buffer containing $10 \mathrm{mM}$ $\mathrm{HCl}$ plus $70 \%$ methanol. One of the simple and practical methods to perform stacking is dissolving the sample in organic solvents and injecting a large volume of sample on the capillary. This leads to concentration of the sample 10-30 folds directly on the capillary (stacking) $[16,17]$. The elution of the sample with a solvent containing methanol allowed to decrease the LOD and to reduce band broadening to obtain sharper peaks. The replacement to an acidic medium has the additional advantage of stabilizing the thiols, allowing preserving the sample for more time before the analyses.

Buffer electrolyte and electrophoretic parameters were considered to obtain an adequate resolution and separation efficiency of peaks in electropherograms, taking the conditions of the sample into account. In this case, a basic BGE was selected to achieve an online electrophoretic preconcentration through sample stacking [18].

Phosphate buffer, although it is one of the most commonly used BGEs, within neutral and weak alkaline $\mathrm{pH}$, may deteriorate the analytical results when analyzing mobile anions [19]. Tris/HCl and carbonate buffer have also been used as basic BGE to obtain an optimum separation and identification of PCs and GSH [20, 21]. However, borate buffer has been used to analyze not only PCs and GSH but also other thiols as Cys and $\gamma$-Glu-Cys [22-24].

Moreover, borate buffer in the neutral to slightly basic range has been found useful as a starting buffer for small molecules, peptides and proteins. For these reasons borate buffer was selected as a feasible reagent to achieve the adequate BGE. 

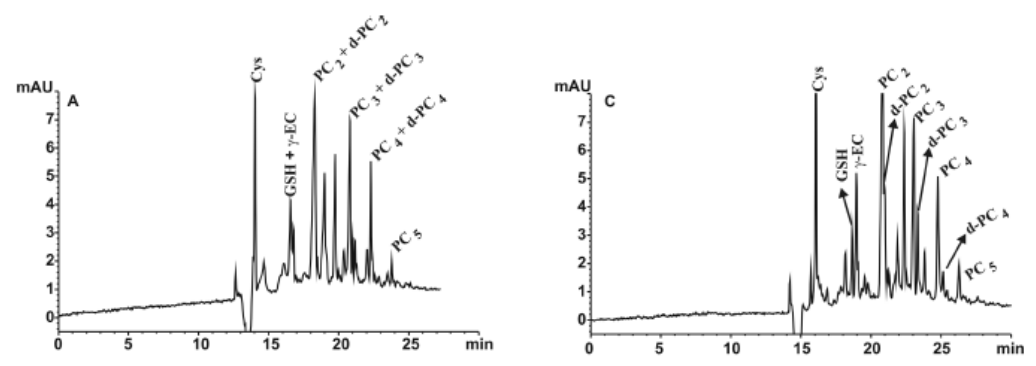

Figure 1. CE separation of

$\mathrm{mBrB}$-thiolic peptides from a biological sample using as buffer $100 \mathrm{mM}$ borate at varying $\mathrm{pHs}$ :
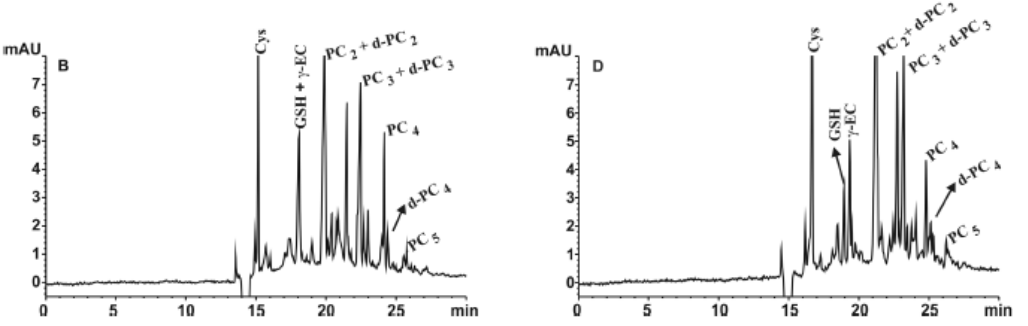

(a) 7.2 ; (b) 7.4 ; (c) 7.6 ; (d) 7.8 . CZE conditions: effective length of $90 \mathrm{~cm} \times 50 \mu \mathrm{m}$ ID $(98 \mathrm{~cm}$ total length) uncoated fused silica

capillary; samples introduced by pressure (50 mbar) for $20 \mathrm{~s}$; applied voltage, $15 \mathrm{kV}$; detection wavelength, $390 \mathrm{~nm}$. Peaks without assignment were not identified thiols.

\section{Effect of $p H$ and concentration of the BGE on the separation}

The $\mathrm{pH}$ and concentration of the BGE are among the most important parameters in a $\mathrm{CE}$ separation. The running buffer $\mathrm{pH}$ plays a key role in $\mathrm{CE}$ by modifying the EOF and overall charges of the analytes (especially in the case of peptides or amino acids), both of which affect the effective mobility and separation efficiency. The effect of running buffer concentration was studied by preparing buffers containing sodium borate concentrations of $25,50,75,100$ and $125 \mathrm{mM}$. All the concentrations evaluated were assayed by varying the $\mathrm{BGE} \mathrm{pH}$ within the $7.1-7.8$ range.

Figure 1 shows the effect of different $\mathrm{pHs}$ had in the separation, in buffers containing sodium borate concentrations of $100 \mathrm{mM}$. As can be seen in the figure, $\mathrm{pH}$ influenced the separation of the peaks significantly. As $\mathrm{pH}$ increased from 7.1 to 7.6, the separation improved.

Although the PCs with different chain length were well separated in all the pHs assayed, PCs co-migrated with their respective desGly-PCs and only when the $\mathrm{pH}$ was 7.6 the separation among them was achieved. With pHs higher than 7.6, desGly-PCs comigrated with PCs again.

The values of RMT showed only slight variations as $\mathrm{pH}$ increased which demonstrates that the increase in this narrow range of $\mathrm{pH}$ has little effect in the charge/mass ratio of the PCs. However, this increase had enough magnitude to allow the separation of desGly-PCs from PCs with only one amino acid of difference.

In $\mathrm{CE}$ the concentration of the electrolyte buffer can be adjusted to enhance the separation performance. In many cases the use of buffers with high concentrations is 
preferable because capillary walls-analytes interactions are suppressed and sample stacking effects are facilitated. However, Joule heating must be carefully controlled.
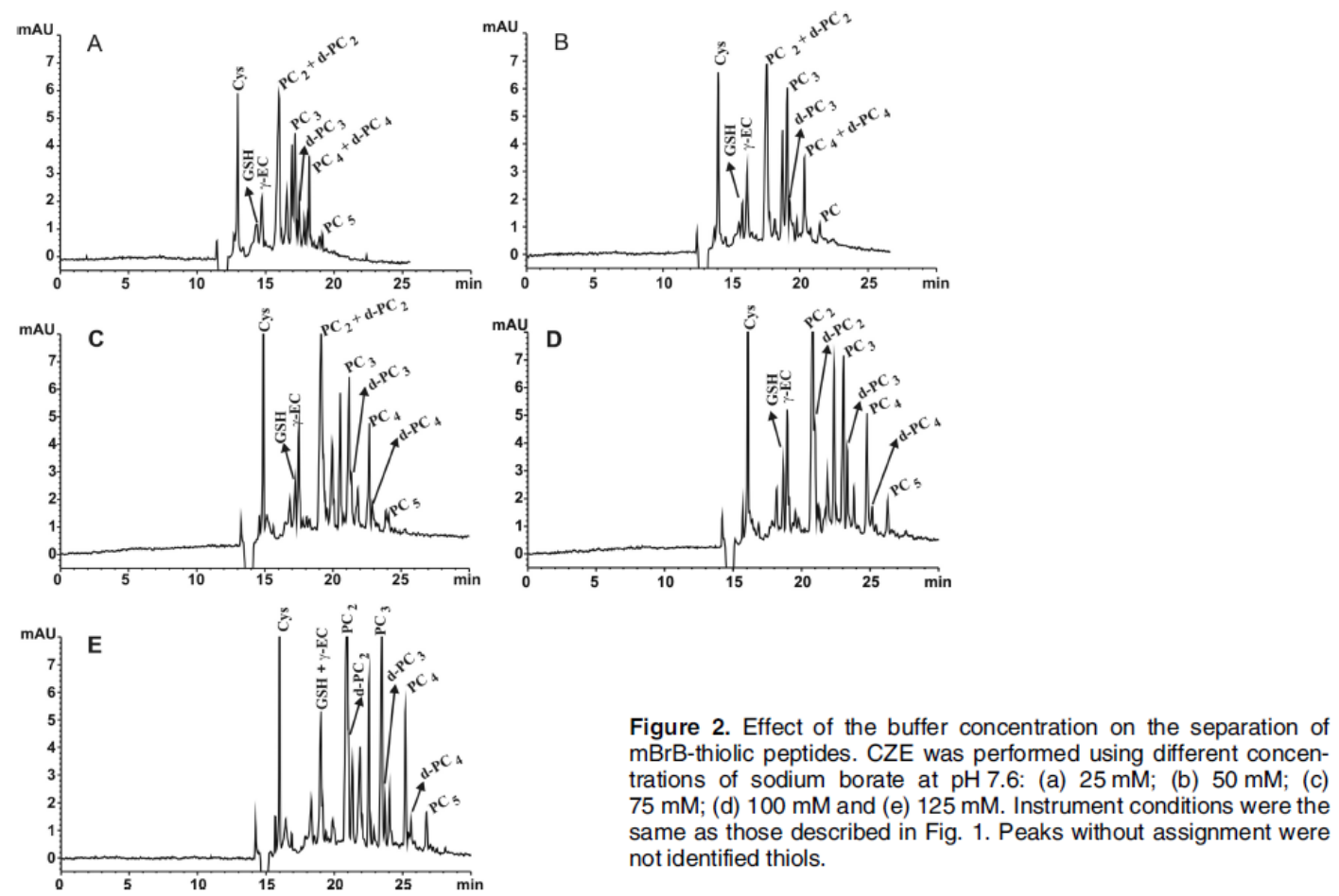

Figure 2 shows the sodium borate concentration effect at the $\mathrm{pH}$ with the best results in the separation. The increase in the sodium borate buffer concentration from 25 to 100 $\mathrm{mM}$ showed an increase in the separation efficiencies with a noticeable change in the height of the peaks but with the concentration of $125 \mathrm{mM}$ the resolution of some peptides get worse. In this way, desGly- $\mathrm{PC}_{3}$ and $\mathrm{PC}_{3}$ can be distinguished in all sodium borate concentrations at $\mathrm{pH} 7.6$ except with the highest concentration; however, the rest of the PCs peaks needed a concentration higher than $50 \mathrm{mM}$ to reach a satisfactory separation from their respective desGly-PCs the concentration of $100 \mathrm{mM}$ being the optimum. Low concentrations (25 and $50 \mathrm{mM}$ ) and $\mathrm{pH}$ higher than 7.3 enabled the separation of the small thiol peptides GSH and $\gamma$-Glu-Cys but if the concentration of sodium borate is increased to 75 and $100 \mathrm{mM}$, an optimal separation is also reached at $\mathrm{pH}$ 7.6. The results indicate that the RMT increased slightly from 25 to $125 \mathrm{mM}$. This increase was higher than with the $\mathrm{pH}$ changes, moreover, the total time of the electropherogram increased substantially due to the decrease in the EOF and the electrophoretic separation of the analytes was better with the exception of the concentration of $125 \mathrm{mM}$ (Fig. 2).

Considering the results obtained with the different assayed electrolytes, a sodium borate concentration of $100 \mathrm{mM}$ and a $\mathrm{pH} 7.6$ was selected as the most suitable for the electrolyte because it yielded the best separation for practically each derivatized thiolic 
peptide. Only desGly- $\mathrm{PC}_{2}$ was not suitably separated from $\mathrm{PC}_{2}$ due to the amount of $\mathrm{PC}_{2}$ which was too high to achieve the separation.

\section{Effect of organic additives}

In order to determine the influence of organic solvents, methanol and trifluoroethanol was added to the BGE composed by sodium borate $100 \mathrm{mMand} \mathrm{pH}$ 7.6. Because of their amino acid composition similarities, the relative electrophoretic separation of this set of related $\mathrm{mBrBpeptides}$ should not be significantly influenced by the addition of an organic solvent. In fact, the addition of these modifiers produced a decrease in conductivity and the resolution only improved slightly with some peaks, but with most of them got worse. Also, migration time increased considerably both with methanol and trifluoroethanol.

For these reasons, organic modifiers were omitted in the BGE, since they did not contribute to improve the analyses.

\section{Effect of applied voltage and capillary length}

The Ohm's law plot was used for the determination of the maximum voltage that can be utilized with the BGE chosen. Linearity in the graphical representation of current versus voltage applied $\left(\mathrm{R}^{2}=0.998\right.$, graphic not shown) was kept in the whole range of voltages assayed. With this condition, the maximum voltage $(+30 \mathrm{kV})$ would not be expected to be problematic and for this reason it was tested to obtain maximum efficiency and to reduce the analysis time. The total time of the electropherogram was lower and peaks were sharper but GSH and $\gamma$-Glu-Cys as well as PCs and desGly-PCs were not well separated. Because of this, voltage was reduced to obtain a compromise between analytical time and resolution.

Otherwise, the use of a shorter capillary also means a shorter analysis time. Initial separations were performed in a capillary of $90 \mathrm{~cm}$ length from inlet to detector. When the capillary was shortened to 70 and $80 \mathrm{~cm}$, the migration time decreased reducing the separation time; however, with these lengths the resolution also decreased considerably. $\gamma$-Glu-Cys peak overlapped with GSH peak and desGly-PCs were not separated (electropherograms not shown).

Considering these results, a capillary with an effective length of $90 \mathrm{~cm}$ combined with an applied voltage of $+15 \mathrm{kV}$ gave a satisfactory separation within a reasonable analysis time. 
Table 1. Analytical performance of the CE method developed

\begin{tabular}{|c|c|c|c|c|c|}
\hline Analyte & Theoretical plates & $\begin{array}{l}\text { Migration time } \\
\text { (\%RSD) }\end{array}$ & Height (\%RSD) & Area (\%RSD) & Resolution \\
\hline Cys & $115957 \pm 1890$ & 1.48 & 1.75 & 1.38 & $1.17 \pm 0.8$ \\
\hline GSH & $96700 \pm 3504$ & 1.62 & 1.9 & 1.71 & $11.25 \pm 0.22$ \\
\hline$\gamma$-Glu-Cys & $74598 \pm 4871$ & 1.65 & 2.64 & 4.3 & $1.05 \pm 0.05$ \\
\hline $\mathrm{PC} 2$ & $54750 \pm 3370$ & 1.77 & 1.68 & 2.47 & $5.47 \pm 0.24$ \\
\hline d-PC2 & $200479 \pm 17008$ & 1.7 & 2.55 & 1.12 & $0.34 \pm 0.02$ \\
\hline PC3 & $105584 \pm 8745$ & 1.89 & 4.46 & 4.15 & $2.35 \pm 0.13$ \\
\hline d-PC3 & $206171 \pm 11266$ & 1.93 & 1.42 & 2.05 & $1.01 \pm 0.05$ \\
\hline PC4 & $110688 \pm 5791$ & 1.98 & 4.09 & 4.89 & $2.94 \pm 0.08$ \\
\hline d-PC4 & $135926 \pm 49207$ & 2.02 & 3.71 & 2.72 & $1.26 \pm 0.09$ \\
\hline PC5 & $160670 \pm 6792$ & 2.05 & 1.7 & 2.3 & $3.71 \pm 0.09$ \\
\hline
\end{tabular}

\section{Method validation}

The validation of the method was carried out using the optimized conditions. The optimal conditions obtained for separating the thiolic peptides derivatized with $\mathrm{mBrB}$ and dissolved in $10 \mathrm{mM} \mathrm{HCl}+0.5 \% \mathrm{v} / \mathrm{v}$ methanol were as follows: $100 \mathrm{mM}$ sodium borate at $\mathrm{pH} 7.60$, effective length of $90 \mathrm{~cm}$ x $50 \mu \mathrm{MID}$ (98 cm total length) uncoated fused silica capillary, pressure injection of 50 mbar for $20 \mathrm{~s}$, applied voltage of $+15 \mathrm{kV}$ and detection wavelength of $390 \mathrm{~nm}$.

Figure $1 \mathrm{C}$ and $2 \mathrm{D}$ show a typical electropherogram with the separation of the different $\mathrm{mBrB}$-thiolic peptides by the procedure developed.

Reproducibility of the migration times of analytes is an important factor in the evaluation of a CE method. The reproducibility of migration time and peak height of the derivatized thiolic peptides under the optimal conditions were tested by repeated injection $(n=6)$ sequentially in a single day to obtain the within-run precision. The RSD of the migration times and the peak height obtained for the within-run precision is shown in Table 1. The values of RSD\% in the migration times obtained for the different peptides identified in the electropherograms ranged from 1.48 to $2.05 \%$. The inter-day precision was obtained by injecting the same biological sample six times on different days. The values of RSD\% for the migration times and for the height obtained for the different peptides identified in the electropherograms ranged from 1.55 to $2.57 \%$ and from 1.11 to $4.9 \%$ respectively. The RSD values of the peak areas of these compounds for the within-run and inter-day precision were less than $6 \%$ in both cases. These results mean a satisfactory analytical precision indicating a good reproducibility of the method.

The number of theoretical plates is a useful measure of the capillary performance. In most of the peaks the number of plates obtained was higher than 100000 (Table 1). The greatest enhancement of separation efficiency was obtained for desGly- $\mathrm{PC}_{3}$ with more than 205000 theoretical plates per metre. The worst efficiency was obtained for $\mathrm{PC}_{2}$ due to the greater quantity of this phytochelatin in the sample. In comparison with [15], the higher number of plates obtained with this improved method shows that it has better 
efficiencies, demonstrating that the separation is better. Also, with the present method, the values obtained in the resolution were suitable to separate themBrB-peptides.

The recovery efficiency was evaluated for Cys and GSH. Recovery was very high for both thiol compounds reaching average values of 91.3 and $99.8 \%$ respectively, with coefficients of variation (\%) of 2.1 and 1.5. Student's t-test to each set of concentrations showed no significant differences in the recovery percentages.

Six-point calibration plot was established by analyzing GSH standard solutions. Six different concentrations that range from 7.5 to $100 \mu \mathrm{M}$ were used in order to do a quantitative analyses of the different thiolic peptides.

With detection at $390 \mathrm{~nm}$, a good linearity between peak area and concentration can be observed in this range of concentrations, with correlation coefficient $R^{2}=0.9991$, the equation obtained being $\mathrm{y}=0.4313 x-0.35$. The LODs and LOQs estimated were 1.41 and $4.69 \mu \mathrm{M}$ respectively with hydrodynamic injection of $20 \mathrm{~s}$ at $50 \mathrm{mbar}$. These quantities mean an additional improvement in relation to LOD and LOQ obtained in [15] with values of 2.8 and $9.59 \mu \mathrm{M}$, respectively.

\section{Concluding remarks}

The results of this study show an adequate procedure for the analyses of thiolic peptides derivatized with $\mathrm{mBrB}$. A CZE method to determine the presence and concentration of low-molecular-mass thiols in complex matrix of biological samples was developed with borate buffer $100 \mathrm{mM}$ pH 7.6 being selected as a suitable electrolyte. The method reported has several advantages. One of the most worthwhile advantages is the simultaneous determination of several low-molecular-mass thiols: Cys, $\gamma$-Glu-Cys, GSH, phytochelatins and desGly-PCs. The precision, accuracy, sensitivity and linearity were determined in a set of validation experiments that indicate that the method possesses high selectivity and accuracy. It should be highlighted that recovery efficiency was 91 and $100 \%$ for Cys and GSH respectively. The LODs and LOQs were 1.41 and $4.69 \mu \mathrm{M}$ respectively.

Therefore, the CZE method described here was demonstrated to be a suitable procedure for the simultaneous determination of different thiol compounds in complex biological samples.

The authors declared no conflict of interest. 


\section{References}

[1] Rausch, T., Wachter, A., Trends Plant Sci. 2005, 10, 503 - 509.

[2] Noctor, G., Arisi, A. C. M., Jouanin, L., Kunert, K. L., Rennenberg, H., Foyer, C. H., J. Exp. Bot. 1998, 49, 623 - 647.

[3] Cobbett, C., Goldsbrough, P., Annu. Rev. Plant Biol. 2002, 53, 159 - 182.

[4] Figueroa, J. A. L., Afton, S., Wrobel, K., Caruso, J. A., J. Anal. At. Spectrom. 2007, 22, $897-904$.

[5] Thangavel, P., Long, S., Minocha, R., Plant Cell Tissue Organ Cult. 2007, 88, 201 216.

[6] Srivastava, S., Mishra, S., Tripathi, R. D., Dwivedi, S., Trivedi, P. K., Tandon, P. K., Environ. Sci. Technol. 2007, 41, 2930 - 2936.

[7] Newton, G. L., Dorian, R., Fahey, R. C., Anal. Biochem. 1981, 114, 383 - 387.

[8] Minchinton, A. I., Int. J. Radiat. Oncol. Biol. Phys. 1984, 10, 1503 - 1506.

[9] Imaizumi, Y., Yamashiro, T., Arikawa, Y., Anal. Sci. 2001, 17, i1325 - 11327.

[10] Chassaing, C., Gonin, J., Wilcox, C. S., Wainer, I. W., J. Chromatogr. B Biomed. Sci. Appl. 1999, 735, 219 - 227.

[11] Mendoza, J., Soto, P., Ahumada, I., Garrido, T., Electrophoresis 2004, 25, 890 - 896.

[12] Tanaka, Y., Higashi, T., Rakwal, R., Wakida, S., Iwahashi, H., J. Pharm. Biomed. Anal. 2007, 44, $608-613$.

[13] Pérez-Rama, M., Torres, E., Abalde, J., Environ. Toxicol. Chem. 2006, 25, 128 - 136.

[14] Fábregas, J., Abalde, J., Herrero, C., Cabezas, B., Veiga, M., Aquaculture 1984, 42, $207-215$.

[15] Pérez-Rama, M., Torres, E., Abalde, J., Electrophoresis 2005, 26, 610 - 620.

[16] Shihabi, Z. K., Curr. Pharm. Anal. 2006, 2, 9-15.

[17] Shihabi, Z. K., Electrophoresis 2002, 23, 1612 - 1617.

[18] Monton, M. R., Imami, K., Nakanishi, M., Kim, J. B., Terabe, S., J. Chromatogr. A $2005,1079,266-273$.

[19] Gebauer, P., Pantuikova, P., Bocek, P., J. Chromatogr. A 2000, 894, 89 - 93.

[20] Musenga, A., Mandrioli, R., Bonifazi, P., Kenndler, E., Pompei, A., Raggi, M. A., Anal. Bioanal. Chem. 2007, 387, 917 - 924. 
[21] Sutter, K., Friebe, S., Krauss, G. J., Int. J. Environ. Anal. Chem. 1999, 74, 167 - 178.

[22] Kubota, H., Sato, K., Yamada, T., Maitani, T., J. Chromatogr. A 1998, 803, 315 320.

[23] Bayle, C., Issac, C., Salvayre, R., Couderc, F., Causse, E., J. Chromatogr. A 2002, $979,255-260$.

[24] Hart, J. J., Welch, R. M., Norvell, W. A., Kochian, L. V., Electrophoresis 2002, 23, 81 $-87$. 